\title{
HIV Treatment Cascade Assessment of a Community-Based Test and Start Model for Key Populations in Lagos State Nigeria: Where Are the Gaps?
}

\author{
Jean Njab*, Sylvia Adebajo, George Eluwa, Elizabeth Shoyemi, Progress Osakwe, Charles Eke, \\ Daniel Offie
}

Population Council, Abuja, Nigeria

Email: ^jnjab@popcouncil.org

How to cite this paper: Njab, J., Adebajo, S., Eluwa, G., Shoyemi, E., Osakwe, P., Eke, C. and Offie, D. (2018) HIV Treatment Cascade Assessment of a CommunityBased Test and Start Model for Key Populations in Lagos State Nigeria: Where Are the Gaps? World Journal of AIDS, 8, 105-117.

https://doi.org/10.4236/wja.2018.83009

Received: December 14, 2017

Accepted: September 18, 2018

Published: September 21, 2018

Copyright $\odot 2018$ by authors and Scientific Research Publishing Inc. This work is licensed under the Creative Commons Attribution International License (CC BY 4.0).

http://creativecommons.org/licenses/by/4.0/

c) (i) Open Access

\begin{abstract}
Background: Community-based test and start (TAS) models have shown the potential to improve clinical outcomes for key populations because early access to treatment will have population level impact by reducing transmission through the promotion and provision of hassle-free quality HIV testing, on the spot ART initiation and unrestricted access to culturally competent health professionals. We assessed the effectiveness of a pioneer community-based test and start (TAS) model for key populations in Lagos along UNAIDS 90/90/90 cascade. Methods: Men who have sex with men (MSM), female sex workers (FSW), and persons who inject drugs (PWID), $>14$ years of age were recruited through peer-referral for HIV testing services (HTS) at a community-based KP-friendly clinic in Lagos between June 2015 and September 2016. The clinic provides comprehensive HIV services, including HIV treatment. Those who test positive are enrolled and provided with TAS services. Using routine service data, we deployed descriptive cross tabulations at $\mathrm{p}<5 \%$ to determine the performance along the 90/90/90 cascade. Results: In total, 8812 KPs comprising MSM (51.6\%), FSW (32.7\%) and PWID (15.7\%) were tested during this period. About one-half (46.4\%) were young KP (15 25 years). The majority (76.1\%) were male, single (86.1\%), almost all (99\%) had at least primary school level education, and about one-quarter $(25.1 \%)$ were employed. Among MSM, 506 (11.1\%) tested positive, 276 (54.5\%) were initiated on ART, of whom 155 conducted viral load testing and 88 (56.7\%) had achieved viral suppression ( $<1000$ copies per milliliter). Among FSW, 88 (3.1\%) tested positive, only $28(31.8 \%)$ were initiated on ART, of whom 15 conducted viral load testing and $9(60 \%)$ achieved viral suppression. Among PWID, of 15 (1.1\%) who tested positive, only 2 (13\%) were initiated on ART
\end{abstract}


and none had conducted viral load testing. Client satisfaction index was 96.1\%. Conclusion: The current community-based model showed excellent capacity to achieve the first 90 goal among target KP communities. However, linkage to care and treatment, adherence, and retention remain major challenges in achieving the second and third nineties at the community level.

\section{Keywords}

HIV, Cascade, Assessment

\section{Background}

Nigeria has the second largest global HIV/AIDS burden and a mixed epidemic driven by low personal risk perception, multiple concurrent sexual partnerships, transactional and inter-generational sex, ineffective and inefficient services for sexually transmitted infections (STIs), and inadequate access to quality healthcare [1] [2]. Though HIV prevalence is on the decline in the general population (3.6\% to $3.4 \%$ ), two episodes of integrated biological and behavioural surveillance surveys have identified three key populations (KP) namely, female sex workers (FSW), men who have sex with men (MSM) and persons who inject drugs (PWI), with prevalence as high as $22.9 \%$ among MSM, $19.4 \%$ among brothel based FSW and 3.4\% among PWID [3] [4]. In addition, while key populations may constitute only about $1 \%$ of the adult population, these high risk groups contribute a significant proportion of the new infections. According to the mode of transmission studies conducted in 2008, FSW, MSM and PWID with their partners contribute as much as $40 \%$ of new infections [5]. Therefore, addressing the comprehensive HIV needs of these target populations remains a priority and strategic step towards reversing the spread of the epidemic in Nigeria.

Unfortunately, unabated stigma, discrimination, criminalization and hostile homophobic environment, coupled with the pervasive insensitivity of health professionals towards key populations have continued to limit access to quality and comprehensive HIV prevention, treatment and care. As a result, key populations often present late for treatment and few are initiated into lifesaving medications including antibiotics and ARV treatment. The 2014 Integrated Biological and Behavioral Surveillance Survey (IBBSS) reported that only 75\% of MSW, $60 \%$ of PWID and 55\% of FSW knew a facility to have HIV testing services (HTS) [3]. This implies that innovative, culturally sensitive and quality service delivery models are needed to reach, test, link and retain KP in care within their communities.

A growing body of evidence seems to suggest that community-based interventions are effective in reducing risky sexual behavior and the incidence of STIs in key populations (KP), improving adherence to ART, and retention in care and treatment [6] [7] [8]. In addition, test and start models have shown the potential 
to improve clinical outcomes for key populations because early access to treatment will have population level impact by reducing transmission through the promotion and provision of hassle-free quality HIV testing, on the spot ART initiation, unrestricted access to culturally competent health professionals, pointof-care viral load testing to monitor viral suppression and adherence in order to optimize clinical outcomes, thereby contributing to achieving the WHO/ UNAIDS 90/90/90 goal.

However, in Nigeria, less than one-fifth of PLHIV are on treatment [9]. ART services are mainly available in specialized secondary and tertiary hospitals thus, limiting access to KP communities. Furthermore, health workers in these facilities lack the cultural sensitivity to reach and meet the health needs of these underserved and marginalized groups in line with the 90/90/90 goal. In this study, we assessed the effectiveness of a HIV community-based test and start model also referred to as "one-stop-shop" (OSS) for key populations along the 90/90/90 cascade in Lagos, Nigeria.

\section{Methods}

\subsection{Study Design and Setting}

We monitored and used service statistics to measure progress toward the 90/90/90 UNAIDS goals [10] of ending the AIDS epidemic by 2020 (reach $90 \%$ of target KPs with HIV testing services, start $90 \%$ of HIV positive clients on ART, achieve $90 \%$ viral suppression after 12 month on therapy) in a community-based test and start (TAS) model in Lagos state, Nigeria from June 2015September 2016. Population Council IRB granted ethics approval and each participant documented consent at the entry point of combination prevention services.

The community-based TAS model, also referred to as one-stop-shop (OSS) for comprehensive HIV prevention and treatment deployed combination prevention and clinical services using a two pronged strategy of demand creation and supply of KP culturally sensitive services. The demand creation prong consisted of a network of trained mobile teams (peer educators/HIV counselors testers), who mapped KP communities and offer client-focused combination prevention intervention (CPI) to their peers including peer education sessions, mobile HIV testing services, condom/lubricant demonstration, forecast and distribution, as well as STI syndromic management. Clients who tested positive were referred to the OSS for initiation to ART. Those who tested negative were advised to visit the OSS at least once a quarter for a retest and access other clinical services (STI treatment including a no-genital warts). The supply prong was driven by a facility based clinical team (nurses, medical doctor, medical laboratory scientist and pharmacist) trained to provide KP culturally sensitive care. Supply services provided at OSS included HIV testing and counseling, anti-retroviral therapy (ART), STI syndromic management, cryotherapy for a no-genital warts, laboratory support services, psychosocial support, condom and lubricant forecast, 
demonstration, messaging and distribution, care and support for HIV infected clients.

Each quarter, a community advisory committee made up of representatives from Lagos state agency for the control of AIDS (LSACA), police action committee on AIDS (PACA), KP communities and KP-focused community based organizations and staff of the OSS, met to address structural barriers (community norms, stigma, sexual violence, harassment, extortion, intimidation and unlawful detention).

\subsection{Study Participants}

Study participants were all key populations (FSW, MSM, PWID) 15 years and above. Participants were recruited by KOLs at hotspots (brothels, bars, bunks, etc) and social events (parties, birthday celebrations and community dialogue meetings) between June 2015 and September 2016. Participants were administered consent at the point of entry during HTS according to national guidelines. Each participant underwent a pre-test counseling, testing according to national algorithm, then post-test counseling including STI syndromic management, risk reduction counseling and linkage to treatment for HIV positive clients.HIV negative participants were encouraged to re-test every three months. All HIV positive participants received the standardized two weeks adherence counseling prior to ART initiation. We estimated a target forecast of 7130 participants (3272 MSM, 2686 FWS and 1172 PWID) based on funding requirement for the period of the intervention and a survey rejection rate of $20 \%$ corresponding to study sample size of 8556 with a $95 \%$ confidence interval of [8129 - 8985] Design effect was 2.

\subsection{Data Collection and Management}

Data were collected on a weekly basis on standardized national prevention and treatment tools using a dedicated electronic health management information system (HMIS). HMIS isan electronic medical records system deployed by Cyber served Nigeria Limited [11] that facilitates data capture, storage, processing and export in an excel format for analysis. Data quality assessment and proficiency testing for program staff (peer educators and clinical staff) were conducted on a quarterly to validate data integrity and services provided, while a client exit interview was administered to those on ART in order to measure client satisfaction index. Data were exported on Microsoft excel and analyzed on SPSS version 19. Descriptive statistics were used to describe participants' characteristics, while cross tabulations were used to measure the performance of the intervention along the cascade at a probability level of $5 \%$.

\subsection{Ethics Approval}

Population Council IRB granted ethics approval and each participant documented consent at the entry point of combination prevention services. 


\section{Results}

In total, 8812 KPs comprising MSM (51.6\%), FSW (32.7\%) and PWID (15.7\%) were tested during this period. About one-half (46.4\%) were young KP (15 - 25 years). The majority (6706; 76.1\%) were male, single (7587; 86.1\%), almost all (8724; 99\%) had at least primary school level education, and about one-quarter (25.1\%) were employed (see Table $1, \mathrm{~N}=8812$ ). The performance of the OSS model relative to the target forecast (see Table 2) showed that all KP subgroups were surpassed by $39 \%$ for MSM, 7\% for FWS and 18\% for PWID.

The cascade assessment among MSM (see Figure 1, N = 4550) indicate that, off the 4550 tested, 506 (11.1\%) were positive, 276 (54.5\%) were initiated on ART, of whom 155 conducted viral load testing and 88 (56.7\%) had achieved viral suppression ( $<1000$ copies per milliliter). The cascade assessment among FSW (see Figure 2, $\mathrm{N}=2879)$ revealed that, off the 2879 tested, $88(3.1 \%)$ were positive, only $28(31.8 \%)$ were initiated on ART, of whom 15 conducted viral load testing and $9(60 \%)$ achieved viral suppression. The cascade assessment among PWID (see Figure 3, $\mathrm{N}=1383$ ) showed that, off the 1383 tested, 15 (1.1\%) were positive, only 2 (13\%) were initiated on ART and none had conducted viral load testing at the end of the study.

The client's satisfaction index (exit form assessment) administered to clients on ART showed that majority of clients (90.2\%) were attended to within $15 \mathrm{mi}$ nutes (see Table 3, $\mathrm{N}=360$ ). The major difficulty in accessing the services was the cost of transportation to the OSS (65\%). Majority (>90\%) reported that they were treated with respect and the OSS was reportedly clean. Additionally, more that $85 \%$ always had access to HIV testing and drugs. Finally, almost all (96.1\%) were satisfied with the quality of services (see Table 3 ) corresponding to 3.2 on a six sigma scale [12].

\section{Discussion}

The aim of this study was to assess the effectiveness of a pioneer communitybased test and start (TAS) model along UNAIDS 90/90/90 cascade goals from HIV prevention to viral suppression (reach $90 \%$ of target KPs with HIV testing

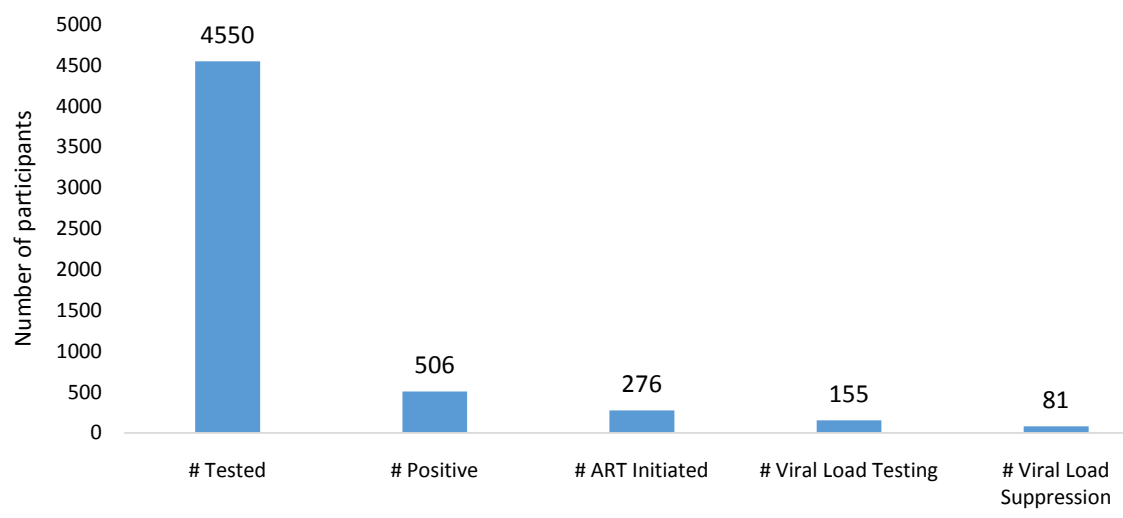

Figure 1. HIV cascade assessment among MSM $(n=4550)$. 
Table 1. Background Characteristics of participants.

\begin{tabular}{|c|c|c|c|}
\hline \multirow{2}{*}{ Characteristics } & \multicolumn{3}{|c|}{$(\mathrm{n}=8812)$} \\
\hline & (n) & $\%$ & $(95 \% \mathrm{CI})$ \\
\hline \multicolumn{4}{|l|}{ Age Group } \\
\hline$<15$ & (35) & $0.4 \%$ & $(0.1-0.9)$ \\
\hline $15-19$ & $(846)$ & $9.6 \%$ & $(8.0-11.6)$ \\
\hline $20-24$ & $(3208)$ & $36.4 \%$ & $(33.6-39.4)$ \\
\hline $25-49$ & $(4459)$ & $50.6 \%$ & $(47.6-53.6)$ \\
\hline$>49$ & (264) & $3.0 \%$ & $(2.1-4.3)$ \\
\hline \multicolumn{4}{|l|}{ Gender } \\
\hline Male & $(6706)$ & $76.1 \%$ & $(73.5-78.6)$ \\
\hline Female & $(2106)$ & $23.9 \%$ & $(21.4-26.5)$ \\
\hline \multicolumn{4}{|l|}{ Marital Status } \\
\hline Single & $(7587)$ & $86.1 \%$ & $(91.4-96.0)$ \\
\hline Married & $(1066)$ & $12.1 \%$ & $(3.4-7.8)$ \\
\hline $\begin{array}{c}\text { Others (Divorces, } \\
\text { Widows/Widowers) }\end{array}$ & (164) & $1.8 \%$ & $(0.4-2.7)$ \\
\hline \multicolumn{4}{|l|}{ Education } \\
\hline No Formal education & $(88)$ & $1 \%$ & $(0.5-1.9)$ \\
\hline Primary & (441) & $5.0 \%$ & $(3.8-6.5)$ \\
\hline Secondary & $(4274)$ & $48.5 \%$ & $(45.4-51.5)$ \\
\hline Tertiary & $(4009)$ & $45.5 \%$ & $(42.5-48.5)$ \\
\hline \multicolumn{4}{|l|}{ Occupation } \\
\hline Student & $(2864)$ & $32.5 \%$ & $(43.7-53.1)$ \\
\hline Unemployed & $(3736)$ & $42.4 \%$ & $(27.8-36.6)$ \\
\hline Employed & $(2212)$ & $25.1 \%$ & $(15.7-23.1)$ \\
\hline \multicolumn{4}{|l|}{ KP reached with HTS } \\
\hline MSM & $(4550)$ & $51.6 \%$ & $(41.9-68.7)$ \\
\hline FSW & $(2879)$ & $32.7 \%$ & $(24.1-43.2)$ \\
\hline PWID & (1383) & $15.7 \%$ & $(9.7-17.8)$ \\
\hline
\end{tabular}

Table 2. Performance of the OSS model relative to the target forecast per key population subgroup.

\begin{tabular}{cccc}
\hline Parameters & MSM & FSW & PWID \\
\hline Target & 3272 & 2686 & 1172 \\
Reach & 4550 & 2879 & 1383 \\
Performance (\%) & $139 \%$ & $107 \%$ & $118 \%$ \\
\hline
\end{tabular}

services, start $90 \%$ of HIV positive clients on ART, achieve viral suppression on 90\% of HIV positive clients after 12 months on ART) in Lagos from June 2015September 2016. Our findings showed that for the first 90, the OSS model 


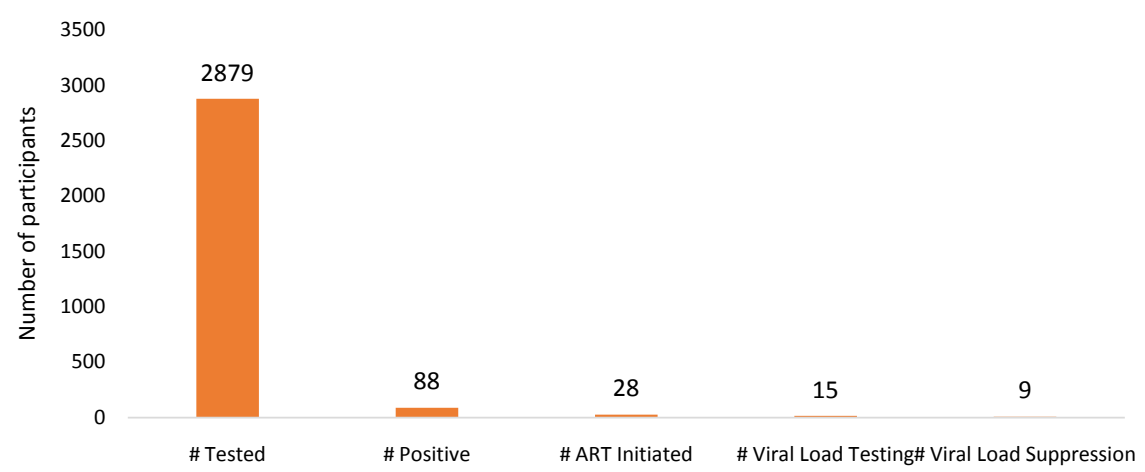

Figure 2. HIV cascade assessment among FSW ( $\mathrm{n}=2879)$.

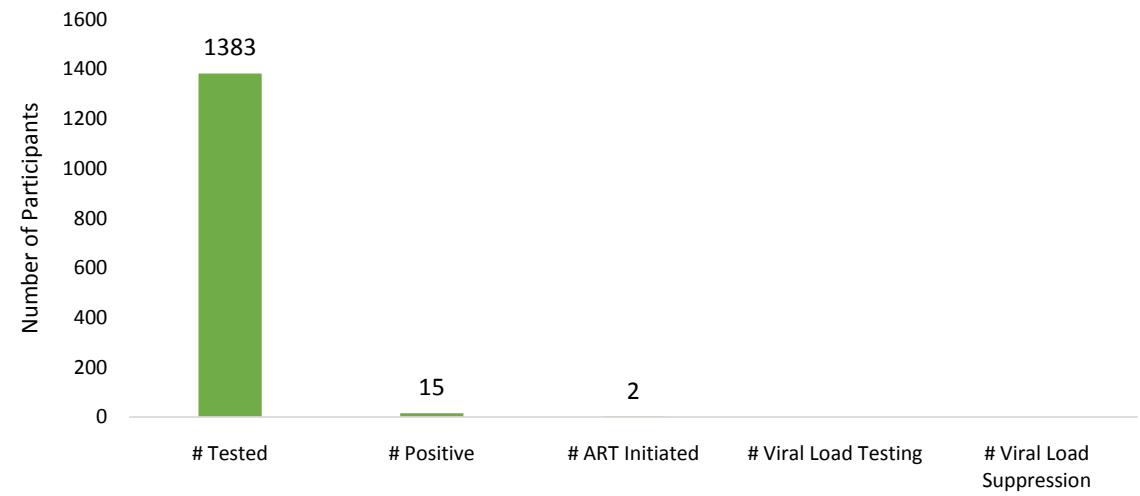

Figure 3. HIV cascade assessment among PWID ( $n=1383)$.

Table 3. Clients' Satisfaction Index at the OSS $(n=360)$.

\begin{tabular}{|c|c|c|c|}
\hline \multirow{2}{*}{ Characteristics } & \multicolumn{3}{|c|}{$(\mathrm{n}=360)$} \\
\hline & (n) & $\%$ & $(95 \% \mathrm{CI})$ \\
\hline \multicolumn{4}{|c|}{$\begin{array}{l}\text { How long did you wait before you } \\
\text { were attended to? }(n=348)\end{array}$} \\
\hline$>30$ minutes & (18) & $5.2 \%$ & $(2.7-7.3)$ \\
\hline $16-30$ minutes & (16) & $4.6 \%$ & $(2.1-6.8)$ \\
\hline$<16$ minutes & $(314)$ & $90.2 \%$ & $(85.2-97.9)$ \\
\hline \multicolumn{4}{|l|}{$\begin{array}{l}\text { What makes it difficult to } \\
\text { come to the OSS? }(n=357)\end{array}$} \\
\hline Cost of Transportation & $(234)$ & $65 \%$ & $(60.3-70.4)$ \\
\hline Personal engagement & $(77)$ & $22 \%$ & $(18.4-27.3)$ \\
\hline Your Working Hours & $(40)$ & $11 \%$ & $(7.7-14.4)$ \\
\hline Unsuccessful Appointment & (6) & $2 \%$ & $(1.7-3.8)$ \\
\hline \multicolumn{4}{|l|}{$\begin{array}{l}\text { Were you treated with respect } \\
\text { at the OSS? }(n=348)\end{array}$} \\
\hline Yes & $(317)$ & $91 \%$ & $(88.5-96.1)$ \\
\hline No & $(31)$ & $9 \%$ & $(5.3-12.4)$ \\
\hline \multicolumn{4}{|l|}{ Is The OSS Clean $(\mathrm{n}=322)$} \\
\hline Yes & $(313)$ & $97.3 \%$ & $(95.3-99.1)$ \\
\hline No & (9) & $2.7 \%$ & $(1.3-5.9)$ \\
\hline
\end{tabular}




\section{Continued}

You could not do HIV test because

there was no test kit? $(\mathrm{n}=358)$

$\begin{array}{lccc}\text { Yes } & (50) & 14 \% & (10.6-18.1) \\ \text { No } & (308) & 86 \% & (81.2-92.4)\end{array}$

You could not access treatment because

There was no drug in stock? $(\mathrm{n}=334)$

Yes

$85.9 \%$

$(43.7-53.1)$

you satisfied with

the services? $(n=359)$

Yes

$96.1 \%$

$(93.4-99.3)^{\star}$

No

(14)

$3.8 \%$

$(1.8-3.4)$

demonstrated excellent capacity to reach all KP subgroups and positivity rates were $11.1 \%$ among MSM, 3.1\% among FSW and 1.1\% among PWID. However for the second 90 and the third 90 , our data showed gaps in terms of linkage to ART initiation (54.5\% for MSM, 13\% for PWID and 10\% for FSW) and viral load suppression (60\% viral suppression rate for FSW and 52.2\% for MSM, relative to $90 \%$ target).

On the first 90 of the cascade our findings were similar to several studies conducted in other parts of the world. In a systematic review of 30 full text articles, Wouter and colleagues [13] reported "unambiguous positive impact of community based ART program on a wide range of aspects, including access and coverage". Of major relevance $18(60 \%)$ studies showed that community based model had the capacity to meet their target populations and $21(70 \%)$ attributed the feasibility and success of community based model to the important role played by lay community members often referred to as community outreach workers (COW). In our study, we have also described a similar role played by mobile HIV testing teams consisting of a mix of peer educators/lay community counselor-testers (also referred to key opinion leaders-KOLs in Nigeria) who create demand for the clinical team. KOLs are mobilizers and influencers trained as peer educators, counselor testers and peer navigators. The success of this demand creation model was documented by Adebajo et al. in 2015 [14] who found a seven fold increase in uptake of HIV testing services using segmented linear regression among trained lay KOLs. Our findings were also consistent with studies from Sharma and colleagues [15], as well as Parker et al. [16], who reported higher reach and uptake of HIV testing services (50\% - 97\%) in community based ART programs than the standard of care (facility-based testing). We found more than $100 \%$ reach on HIV testing services relative to the target forecast, suggesting an effective demand creation strategy at the community level.

However, it is pertinent to note that, this directional similarity in findings masks a wide diversity in study design, sampling methods, target population 
reach rate and testing yield, which may all impact on program outcomes. While we designed a cross sectional study with a peer led snow ball sampling method for key populations, other peer reviewed study designs cited above varied from simple descriptive reports to retrospective cohort studies and cluster randomized trials, all among general populations. Evidence has shown that general population sampling methods are not sensitive to key populations, therefore marked differences in sampling methods and designs usually account for observed variability in HTS outputs (50\% - 100\%) [17] [18] [19] [20]. Though the scale of evidence will place significant value on randomized trials, our study is the first evidence of a cascade assessment among key populations in Nigeria in particular and West Africa in general, with two similar strategies documented in other parts of Africa [21] [22].

In Zambia [23], the success of the TAS model strongly emphasized 1) shifting the community mindset to understand that early initiation of ART is associated with the likelihood of full viral suppression on ART, extremely low probability of HIV transmission and rapid reduction in new infections; 2) investing in community engagement and empowerment of community leaders for long term behavior maintenance and sustainability; 3) using real-time data collection tools and providing feedback to the community in order to strengthen the bond between the project team and community members. The gaps observed on the second 90 (54.5\% linkage to ART for MSM, 13\% for PWID and 10\% for FSW) and third 90 (60\% viral suppression rate for FSW and 52.2\% for MSM, relative to $90 \%$ target) strongly suggests the need to shift the community mindset in Nigeria, from knowledge of HIV status only to the benefits of early ART initiation and achieving community viral suppression, while harnessing innovative tools and technologies to strengthen the bond between the project team and community members.

Data from other settings also showed $40 \%$ - $80 \%$ gap, particularly in the second $90 \%$. A study in Washington, District of Columbia (DC) reported only $50 \%$ acceptance of referral to ART provision centres among those testing HIV-positive [24]. A national testing program in South Africa reported successful testing of 1.7 million individuals between April and July 2010 yet, of 300,000 HIV-positive subjects, only half (50\%) were referred to any related health services and only an additional 3000 initiated ART during the first two months of the program [25]. Barriersto accessing care included limited accessibility, coordination of services and lack of community engagement in program planning [26]. Our data on client satisfaction index (Table 3) showed that the cost of transportation to the OSS and by implication the distance to the OSS was the major barrier to access care at the OSS, though overall clients' satisfaction rate was $96.1 \%$ corresponding to 3.2 on the sigma scale. Personal communication with some clients at the OSS indicated that they spent $\$ 3-6$ for a round intra-city trip to the OSS. This cost is prohibitive for most clients (64.9\%) who have no stable source of income (students and unemployed, see Table 1). In the face of competing socio-economic demands and poor health seeking behaviors 
such clients easily deprioritize their health needs in favour of basic needs like food, clothing and internet connectivity. In order to address this challenge, most studies [27] [28] [29] [30] [31] provide transportation refund/incentive to study participants. While this may be justified as compensation for participation in a study, most donors will not accommodate incentive for clients in service delivery implementation. Consequently, future OSS model in Nigeria should consider differentiated mobile service delivery models that will provide TAS to KPs in their immediate social networks (at hotspots, parties, recreation centres where the cost of transportation is a delight and not a burden), harnessing innovative mobile ART delivery and viral load technologies that will effectively close the gap between testing and linkage to ART on one hand, while promoting retention in care in order to achieve sustainable viral suppression on the other hand.

\section{Conclusion}

The current OSS model effectively achieved the first 90 UNAIDS goal among target KP communities. However, there are major gaps in achieving the second and third nineties. Distance and cost of transportation to the OSS appear to constitute a major barrier to linkage and retention in care for these underserved mobile communities. Therefore deploying innovative cluster mobile TAS services in high HIV testing yield KP communities may reduce these gaps and present better prospects of achieving the full 90/90/90 cascade among key populations in Nigeria.

\section{Acknowledgements}

The study was conducted by Population Council-Nigeria with the technical support of the U.S. Department of Defense Walter Reed Program Nigeria (DOD WRP-N), Nigeria.

\section{Authors' Contributions}

NJ conceptualized the study design and implementation. SE, OP, OD and CE coordinated the data collection and entry. AS and GE contributed to manuscript review.

\section{Funding}

This study is supported by the U.S. President's Emergency Plan for AIDS Relief (PEPFAR) a cooperative agreement between the Henry M. Jackson Foundation for the Advancement of Military Medicine, Inc., the U.S. Department of Defense Walter Reed Program Nigeria (DOD WRP-N), Nigeria and The Population Council-Nigeria.

\section{Prior Presentation}

This work has not been presented at any forum, meeting, workshop or conference. 


\section{Disclaimer}

The content is solely the responsibility of the authors and does not necessarily represent the official views of Henry M. Jackson Foundation for the Advancement of Military Medicine, Inc. and the U.S. Department of Defense, other funders or any of the collaborating institutions.

\section{Conflicts of Interest}

The other authors have no competing interests to disclose.

\section{References}

[1] UNAIDS (2014) Epidemiology Fact Sheet on HIV and AIDS in Nigeria.

[2] Federal Republic of NIGERIA, GLOBAL AIDS RESPONSE Country Progress Report Nigeria (GARPR) ABUJA, NIGERIA, National Agency for the Control of AIDS (NACA), 2015.

[3] Federal Ministry of Health (2010) Integrated Biological and Behavioural Surveillance Survey.

[4] Federal Ministry of Health (2014) Integrated Biological and Behavioural Surveillance Survey.

[5] Federal Republic of NIGERIA, Mode of Transmission, ABUJA, NIGERIA, National Agency for the Control of AIDS (NACA), 2008.

[6] Maek-a-nantawat, W., Phanuphak, N., Teeratakulpisarn, N., Pakam, C., Kanteeranon, T., Chaiya, O., Mansawat, T., Teeratakulpisarn, S., Nonenoy, S., Ananworanich, J. and Phanuphak, P. (2014) Attitudes toward, and Interest in, the Test-andTreat Strategy for HIV Prevention among Thai Men Who Have Sex with Men. AIDS Care, 26, 1298-1302. https://doi.org/10.1080/09540121.2014.911810

[7] Adebajo, S.B., Eluwa, G.I., Allman, D., Myers, T. and Ahonsi, B.A. (2012) Prevalence of Internalized Homophobia and HIV Associated Risks among Men Who Have Sex with Men in Nigeria. African Journal of Reproductive Health, 16, 21-28.

[8] World Health Organization (2015) 978924150892 6: Consolidated Guidelines HIV Testing Services 5Cs: Consent, Confidentiality, Counselling, Correct Results and Connection.

http://apps.who.int/iris/bitstream/handle/10665/179870/9789241508926_eng.pdf;se quence $=1$

[9] Dodd, P.J., Garnett, G.P. and Hallett, T.B. (2010) Examining the Promise of HIV Elimination by “Test and Treat” in Hyper-Endemic Settings. AIDS, 24, 729-735. https://doi.org/10.1097/QAD.0b013e32833433fe

[10] UNAIDS (2014) 90-90-90: An Ambitious Treatment Target to Help End the AIDS Epidemic.

[11] CyberServe Nigeria Limited (2016) Electronic Medical Record for Routine Data Capture. No 4 Sam Pedro Close, Massana Street, Wuse Zone 1, Abuja.

[12] Parasuraman, A., Zeitham, V.A. and Berry, L.L. (1985) A Conceptual Model of Service Quality and Its Implications for Future Research. Journal of Marketing, 49, 41-50. https://doi.org/10.2307/1251430

[13] UNAIDS (2013) Global Report: UNAIDS Report on the Global AIDS Epidemic 2013.

[14] Wouters, E., Damme, W.V., Rensburg, D.V., Masquiller, C. and Meulemans, H. 
(2012) Impact of Community-Based Support Services on Antiretroviral Treatment Programme Delivery and Outcomes in Resource-Limited Countries: A Synthetic Review. BMC Health Services Research, 12, 194. https://doi.org/10.1186/1472-6963-12-194

[15] Adebajo, S.B., Eluwa, G.I., Njab, J., Ayodeji, O., Ukwuije, F., Ahonsi, B. and Lorenc, T. (2015) Evaluating the Effect of HIV Prevention Strategies on Uptake of HIV Counselling and Testing among Male Most-at-Risk-Populations in Nigeria: A Cross-Sectional Analysis; Sexually Transmitted Infections, 91, 555-560.

[16] Sharma, M., Ying, R., Tarr, G. and Barnabas, R. (2015) Systematic Review and Meta-Analysis of Community and Facility-Based HIV Testing to Address Linkage to Care Gaps in Sub-Saharan Africa. Nature, 528, s77-s85.

https://doi.org/10.1038/nature16044

[17] Parker, L.A., Jobanputra, K., Rusike, L., Mazibuko, S., Okello, V., Kerschberger, B., Jouquet, G., Cyr, J. and Teck, R. (2015) Feasibility and Effectiveness of Two Community-Based HIV Testing Models in Rural Swaziland. Tropical Medicine and International Health, 20, 893-902. https://doi.org/10.1111/tmi.12501

[18] McCreesh, N., Frost, S.D., Seeley, J., Katongole, J., Tarsh, M.N., Ndunguse, R., Jichi, F., Lunel, N.L., Maher, D., Johnston, L.G., Sonnenberg, P., Copas, A.J., Hayes, R.J. and White, R.G. (2012) Evaluation of Respondent-Driven Sampling. Epidemiology, 23, 138-147. https://doi.org/10.1097/EDE.0b013e31823ac17c

[19] Rhodes, S.D., Malow, R.M. and Jolly, C. (2010) Community-Based Participatory Research: A New and Not-So-New Approach to HIV/AIDS Prevention, Care, and Treatment. AIDS Education and Prevention, 22, 173-183. https://doi.org/10.1521/aeap.2010.22.3.173

[20] Chamie, G. (2014) Uptake of Community-Based HIV Testing during a Multi-Disease Health Campaign in Rural Uganda. PloS ONE, 9, e84317. https://doi.org/10.1371/journal.pone.0084317

[21] Brown, L.B. (2011) HIV Partner Notification Is Effective and Feasible in Sub-Saharan Africa: Opportunities for HIV Treatment and Prevention. JAIDS Journal of Acquired Immune Deficiency Syndromes, 56, 437-442. https://doi.org/10.1097/QAI.0b013e318202bf7d

[22] Skovdal, M., Nyamukapa, C., Wamoyi, J., Ddaaki, W., Bukenya, D., Renju, J., McLean, E., Moshabela, M., Seeley, J., Bonnington, O. and Wringe, A. (2016) Opportunities and Challenges for "Test-and-Treat": Insights from Eastern and Southern Africa.

[23] Mulongo, S. (2015) Applying Innovative Approaches for Reaching Men Who Have Sex with Men and Female Sex Workers in the Democratic Republic of Congo. Journal of Acquired Immune Deficiency Syndromes, 68, S248-S251. https://doi.org/10.1097/QAI.0000000000000449

[24] Lockman, S. (2010) Test and Treat Strategy for HIV in Resource Limited Settings. Medscape-Sep03, HIV/AIDS @ 2010 WebMD.

[25] Walensky, R.P., Paltiel, A. and Losina, E. (2010) Test and Treat DC: Forecasting the Impact of a Comprehensive HIV Strategy in Washington DC. Clinical Infectious Diseases, 51, 392-400. https://doi.org/10.1086/655130

[26] Brendan, M.-B., Neil, L., Jacob, B. and Atheendar, S.V. (2016) Changes in Self-Reported HIV Testing during South Africa's 2010/2011 National Testing Campaign: Gains and Shortfalls. Journal of the International AIDS Society, 19, 20658. https://doi.org/10.7448/IAS.19.1.20658

[27] Posse, M., Meheus, F., van Asten, H., van der Ven, A. and Baltussen, R. (2008) Bar- 
riers to Access to Antiretroviral Treatment in Developing Countries: A Review. Tropical Medicine \& International Health, 13, 904-913. https://doi.org/10.1111/j.1365-3156.2008.02091.x

[28] Charurat, M., Emmanuel, B., Akolo, C., Keshinro, B., Nowak, R., Kennedy, S., Orazulike, I., Ake, J., Njoku, O., Baral, S. and Blattner, W. (2015) Uptake of Treatment as Prevention for HIV and Continuum of Care among HIV-positive Men Who Have Sex with Men in Nigeria. Journal of Acquired Immune Deficiency Syndromes, 68, S114-S123. https://doi.org/10.1097/QAI.0000000000000439

[29] Keshinro, B., Crowell, T., Nowak, R., Adebajo, S., Peel, S., Gaydos, C., Rodriguez-Hart, C., Baral, S., Walsh, M., Njoku, O., Odeyemi, S., Ngo-Ndomb, T., Blattner, W., Robb, M., Charurat, M. and Ake, J. (2016) High Prevalence of HIV, Chlamydia and Gonorrhoea among Men Who Have Sex with Men and Transgender Women Attending Trusted Community Centres in Abuja and Lagos, Nigeria. Journal of the International AIDS Society, 19, 21270.

[30] Nachega, J.B., Adetokunboh, O., Olalekan, A., Knowlton, U., Altice, F., Schechter, M., Galárraga, O., Geng, E., Peltzer, K., Chang, L., Cutsem, G., Jaffar, S., Ford, N., Mellins, C., Remien, R. and Mills, E. (2016) Community-Based Interventions to Improve and Sustain Antiretroviral Therapy Adherence, Retention in HIV Care and Clinical Outcomes in Low- and Middle-Income Countries for Achieving the UNAIDS 90-90-90 Targets. Current HIVIAIDS Reports, 13, 241-255. https://doi.org/10.1007/s11904-016-0325-9

[31] Mukherjee, J., Barry, D., Weatherford, R., Desai, I. and Farmer, P. (2016) Community-Based ART Programs: Sustaining Adherence and Follow-Up. Current HIVIAIDS Reports, 13, 359-366. https://doi.org/10.1007/s11904-016-0335-7 